\title{
Gravidez na Adolescência: um Novo Olhar
}

Resumo: A gravidez na adolescência constitui tema de grande relevância na realidade social brasileira. $\bigcirc$ enfoque tradicional relaciona a gravidez como indesejada e decorrente da desinformação sexual das jovens. O presente trabalho questiona essa posição, postulando a importância do significado individual da gravidez, que corre paralelo ao desejo universal de ter ou não ter um filho, bem como a noção de uma "gravidez social" determinada por fatores culturais e psicológicos que particularizam o significado da maternidade em adolescentes de classes populares. Conclui-se pela necessidade de reformulação das políticas públicas para com essa população.

Palavras-Chave: Gravidez, adolescência, fatores psicossociais, políticas públicas.

Diana Dadoorian

Doutoranda em Psicologia Clínica e Psicopatologia pela Universidade Paris VIII,França. Mestre em Psicologia Clínica pela PUC/RIO. Especialista em Psicanálise pela USU/RJ. Autora do Iivro "Pronta para Voar: um Novo Olhar sobre a Gravidez na Adolescência" (Rio de Janeiro: editora Rocco, 2000).

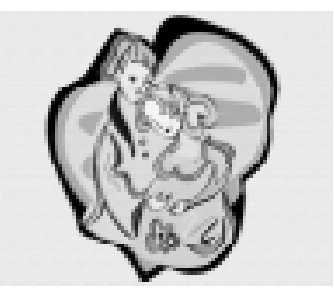

Abstract: Teenage pregnancy is a relevant theme nowadays. The traditional focus relates the undesirable teenage pregnancy to social changes in sexuality and to the lack of sexual information. The present study contests this position postulating the importance of the significance of an individual pregnancy, as well as the universal desire of having or not a baby in adolescence, determined by cultural and psychological aspects that particularize the meaning of moikerhood in popular classes of adolescents. The conclusions point out the necessity of public policy reformulation.

Key Words: Pregnancy, teenage, psicossocial models, public policies.

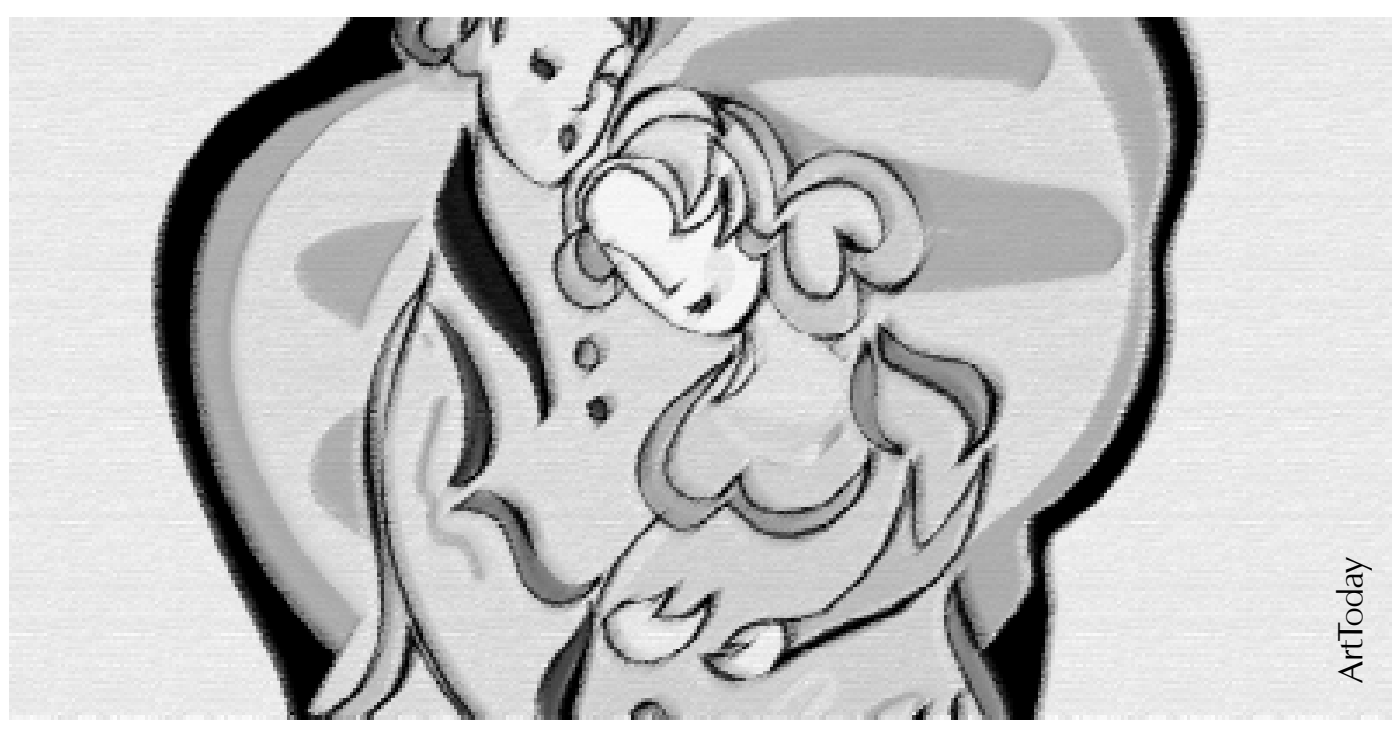

Nos últimos anos, a incidência de gravidez na adolescência vem aumentando significativamente, tanto no Brasil como no mundo. No Brasil, observase que, apesar do declínio das taxas de fecundidade desde o início dos anos 70, é cada vez maior a proporção de partos entre as adolescentes em comparação com o total de partos realizados no País. Segundo dados estatísticos do SUS relativo a 2000, dos 2,5 milhões de partos realizados nos hospitais públicos do país, 689 mil eram de mães adolescentes com menos de 19 anos de idade. A maioria das adolescentes grávidas pertence às classes populares.

Os elevados índices estatísticos de gravidez na adolescência provocaram um maior interesse sobre essa questão por parte dos profissionais de saúde brasileiros. A literatura existente relaciona essa situação às mudanças sociais ocorridas na esfera da sexualidade, as quais provocaram maior liberalização do sexo, sem que, simultaneamente, fossem transmitidas informações sobre métodos contraceptivos para os jovens. Segundo esses profissionais de saúde, a gravidez na adolescência é indesejada, sendo enfocada como um "problema" que deve ser solucionado através da diminuição do número de gravidezes nessa população. A fórmula encontrada para "resolver" essa questão se reduz aos programas de informação sexual.

Esse enfoque apresenta lacunas na compreensão do tema, sendo insuficiente para explicar a complexidade do fenômeno. 
Ora, nos dias de hoje, em pleno século XXI, ainda é possível falar que os jovens não têm informação sexual?

Poderíamos, ao contrário, nos perguntar porque as adolescentes continuam engravidando atualmente se o acesso à informação é justamente muito mais fácil hoje em dia. Basta comprar uma revista na banca de jornal que encontramos todo o tipo de informação sobre contraceptivos, com ilustrações e tudo o mais. Isso para não falar da televisão, da internet, dos cursos de educação sexual existentes em muitos hospitais e escolas e, principalmente, da possibilidade de consultar um ginecologista, e, em muitos casos, com a consulta paga pela própria mãe.

Por que, então, as adolescentes continuam engravidando?

Na tentativa de compreender melhor essa questão, é importante focaliz o olhar sobre o que dizem essas jovens sobre a sua gravidez.

Apesar das situações dramáticas que essa situação Ihes acarreta, como, por exemplo, o abandono dos estudos ou o seu adiamento, maior dependência econômica dos pais, visto que a maioria das jovens continua morando com os pais após o nascimento do filho, já que o pai da criança é, na maioria dos casos, também adolescente; mesmo com todas essas dificuldades, é bastante comum ouvirmos a adolescente dizer que está contente com a perspectiva de ser mãe e que quer ter um filho.

Portanto, ao se privilegiar a fala das adolescentes sobre o seu estado, percebe-se que essa gravidez é desejada por elas, desempenhando, assim, um determinado papel na sua vida psíquica e social, daí a importância de realizar um estudo mais sistemático dos aspectos psicossociais aí presentes. A constatação do estado de grande desamparo e desorientação em que se encontram as jovens e suas famílias frente a essa nova situação, que provoca muitas mudanças e questionamentos em toda a família, motivou-nos a estudar mais sistematicamente essa questão (Dadoorian, 1994; Dadoorian, 2000).

\section{Os Modelos Familiares}

A gravidez em adolescentes de classes populares foi estudada a partir da investigação dos modelos familiares e da classe social e, por conseguinte, da articulação entre família - adolescente grávida classe social.

A família passou por várias mudanças até chegar à nossa atual concepção. Esse processo de cons- trução da família está baseado na articulação entre a história da família e a história da infância, com o surgimento de um "sentimento de família" e de um "sentimento de infância" (Ariès, 1981).

A história da família brasileira nasce na família patriarcal e a família brasileira contemporânea ainda está impregnada desse modelo. Um trabalho realizado sobre a concepção de família em dois grupos sociais da cidade do Rio de Janeiro com mulheres das classes baixas e as das classes médias mostrou que existe um modelo de arranjo familiar único para ambas as classes, o modelo da família patriarcal, que determina as relações de poder na sociedade brasileira. Ele é formado por um núcleo central que abrange o casal e seus filhos e por uma periferia composta por agregados e empregados. Esse modelo, no entanto, constitui um "ideal" para as famílias de classes baixas, só sendo possível de se realizar nas famílias de classe média. Os arranjos familiares são, assim, constituídos em função de circunstâncias econômicas, sociais e históricas segundo as diferentes classes sociais (Lo Bianco, 1986).

Esse fato pode ser verificado no projeto de vida de adolescentes grávidas de classes populares. Todas as jovens entrevistadas relataram a vontade de ter a sua casa e de residir com o marido ou namorado e o filho, o que geralmente não poderia ocorrer devido à sua situação econômica (Dadoorian, 1994).

A psicanálise também traz contribuições relevantes acerca da família, que se traduz no conceito de Complexo de Édipo. O Édipo se refere à existência de um complexo universal com o qual todos nós estamos psiquicamente envolvidos, e que possibilita a formação do sujeito enquanto um ser social e um ser desejante, marcando a nossa entrada na cultura e separando-nos da nossa raiz animal.

O Édipo é um complexo familiar presente em todas as famílias humanas. Além de formador da subjetividade dos sujeitos, ele possui uma função social que se traduz pela transmissão dos valores morais, éticos e sociais, tendo como eixo norteador a posição econômica e cultural de cada família na sociedade.

Em geral, uma família pertencente às classes populares brasileiras tende a educar os filhos com vistas à obtenção de empregos para ajudar no orçamento familiar. O casamento é algo que pode ocorrer precocemente, sendo acompanhado, muitas vezes, de vários filhos. Uma família da classe média, por sua vez, já prioriza a atividade intelectual dos seus jovens. O casamento é, geralmente, adiado para após o término dos estudos.
"Soube sobre

métodos aqui no

hospital, sobre pílula,

camisinha. Já usei

pílula, o médico me

deu, mas parei

porque enjoova e

porque queria

engravidar"

Fátima

(Dadoorian, 2000a, p.14) 
Observamos que a reação das famílias das adolescentes diante da gravidez de suas filhas varia de acordo com a classe social. As famílias das jovens de classes populares apresenta uma melhor aceitação dessa situação, especialmente a mãe e a avó, contrariamente às famílias das adolescentes de classe média, que não desejam a gravidez das filhas adolescentes (Silva \& Pinotti,1987).

\section{Feminilidade e Maternidade}

Mas então, o que querem as mulheres? Não existe uma resposta única para essa pergunta de

Freud. cada mulher terá a sua própria resposta. as adolescentes grávidas entrevistadas nesta pesquisa deram a sua resposta: elas querem ser mães.

A questão do feminino na teoria psicanalítica está intimamente relacionada com a maternidade. Freud (1905) mostra que é na adolescência que se dá a finalização do processo de construção da sexualidade, através da capacidade do jovem de procriar, processo esse que se inicia na mais remota infância. Esse momento é bastante importante para a espécie e fruto de muitas angústias para o jovem. No caso específico da menina, será através do desejo de ser mãe que ela se tornará mulher. Assim, para Freud, o caminho que leva à feminilidade se dá por meio da maternidade. A maternidade se coloca, assim, como um atributo que caracteriza o feminino. Através do filho, um ser que é uma extensão do seu próprio corpo, a mulher se sente plena, nada Ihe falta. $O$ filho funciona como um objeto que completa as suas carências e os seus desejos mais íntimos. O desejo de ter um filho, isto é, o desejo de ter o falo, é algo bastante forte no inconsciente feminino (Freud, 1931).

"O que quer uma mulher?", indaga Freud. Como nos diz Hassoun (1995), se a psicanálise foi capaz de dar conta do desejo das mulheres, ela continua impotente perante o querer feminino, que não coincide com o seu desejo. Ainda existe um caminho a ser percorrido para se explicar a feminilidade.

Mas então, o que querem as mulheres? Não existe uma resposta única para essa pergunta de Freud. Cada mulher terá a sua própria resposta. As adolescentes grávidas entrevistadas nesta pesquisa deram a sua resposta: elas querem ser mães. É importante, então, tentar localizar a origem do desejo de ter um filho na adolescência.

A importância do meio social na determinação do papel feminino nos ajuda a compreender o papel da mulher na sociedade, papel que é transmitido às adolescentes, influenciando as suas escolhas e os seus projetos de vida.

Atualmente, depois de todas as mudanças sociais por que passamos, o papel da mulher de classe média brasileira não se limita ao papel de mãe, estendendo-se também a outras atividades, como a realização profissional. Entretanto, apesar de essas mulheres exercerem outros papéis sociais, a maternidade continua sendo um atributo essencialmente feminino (Lo Bianco, 1985).

As vivências e as representações sobre a família e a inserção da mulher nesse núcleo foram estudadas em um grupo de mulheres faveladas, e observouse que a internalização da ideologia patriarcal e a divisão de papéis sexuais reforçam a definiç̧ão da identidade feminina através da família, ou seja, ser mulher nessa comunidade é sinônimo de ser filha, esposa ou mãe (Salem,1981).

Existe uma diferença de perspectiva em relação ao papel social desempenhado pela mulher, o seu nível sócio-econômico e a gravidez na adolescência. Um estudo realizado por Doering (1989) com adolescentes grávidas mostrou que as adolescentes de classe média atendidas em clínica privada rejeitavam a gravidez, afirmando que essa situação iria atrapalhar as suas perspectivas de estudo e de trabalho, visto que a maternidade não é prioridade nessa classe social. Entre as adolescentes atendidas em hospital público, 58\% referem uma maior aceitação da gravidez por "gostarem de criança". A maternidade aparece como a única perspectiva de vida para essas jovens de classes populares, onde o papel social mais importante por elas desempenhado é o de ser mãe.

\section{A Gravidez na Adolescência: a nossa Hipótese}

A partir da pesquisa realizada, procurou-se articular o enfoque sociológico e antropológico com a teoria psicanalítica acerca da sexualidade feminina e do narcisismo. Dessa correlação, podem-se destacar dois fatores principais como os determinantes da gravidez em adolescentes: os fatores biológicos e os fatores não-biológicos, nos quais se inserem os aspectos culturais e os psicológicos.

Freud (1905) mostra que na puberdade se operam mudanças visando à maturidade sexual. A pulsão sexual se unifica em torno de um único objetivo, que é a função reprodutora. O corpo da adolescente sofre, assim, transformações e mudanças orgânicas que têm por objetivo a reprodução da espécie humana. Esse processo orgânico se expressa através de uma grande pressão hormonal, que impulsiona a adolescente a testar esse aparelho. Surge, então, o interesse pelo sexo, e desse ato decorre, freqüentemente, a gravidez. Os trabalhos de Figueiredo mostram a grande influência que o biológico exerce no psicossocial.

A essa gravidez, fruto da estreita relação entre o corpo e a pulsão sexual, denominaremos aqui de "gravidez hormonal". A partir daí, dois desfechos se colocariam para a adolescente: o desejo negativo 
de ter o filho, expresso no aborto, e o desejo positivo de ter o filho, situado na maternidade. Assim, esse desejo positivo ou negativo de ter um filho na adolescência é um fenômeno universal, visto que pode ocorrer com todas as adolescentes, indistintamente. Os fatores não-biológicos, ou seja, os aspectos culturais e psicológicos, é que irão determinar o destino dessa gravidez hormonal (Dadoorian, 1994).

\section{Metodologia}

Foram realizadas vinte entrevistas semi estruturadas com adolescentes grávidas de classes populares, de 14 a 17 anos de idade, no Instituto Fernandes Figueira no Rio de Janeiro. O modelo de entrevista foi elaborado a partir de sete temas que se referem a: dados pessoais, vida familiar (estrutura e dinâmica), vida escolar, atividade sexual e episódio da gravidez, dados de informação e educação sexual, projetos de vida. A análise das entrevistas se baseou no estudo dos aspectos psicossociais relacionados à gravidez nesse grupo de adolescentes, destacando-se o enfoque psicanalítico da questão e suas implicações na análise de suas motivações, desejos e fantasias.

\section{Resultados e Discussão}

Esta pesquisa investigou a função do desejo da adolescente na sua gravidez.

\section{O significado inconsciente do filho}

Sonia

"Eu sempre quis ter um filho, não sei por quê. Apesar de eu ser muito nova, né! Mas eu quis experimentar, aí eu parei de tomar o remédio" (Dadoorian, 2000a, p. 144).

A curiosidade em testar o seu aparelho reprodutor é desencadeada pela atividade hormonal ocorrida nesse período da vida, que leva ao ato sexual. As jovens iniciam a sua vida sexual logo após a primeira menstruação e engravidam em um curto período de tempo. A gravidez certifica para a adolescente que o seu corpo já está preparado para a concepção. A confirmação da sua capacidade reprodutiva desencadeia um sentimento de surpresa (não esperavam a gravidez), onde ela pode constatar que não é mais menina, e, sim, mulher. Pode-se dizer que essas adolescentes estabelecem uma equivalência onde exercer a sexualidade significa ter filho, o qual demarca a sua entrada na vida adulta.

Nas classes populares essa gravidez hormonal se transforma, freqüentemente, numa gravidez "simbólica", isto é, em uma maternidade precária. Apesar das circunstâncias sociais desfavoráveis, o desejo de ter o filho era predominante entre essas jovens, sendo necessário localizar a origem desse desejo.

A ocorrência de gravidez na adolescência é um fato rotineiro e comum nessa classe social. As colegas das jovens entrevistadas, suas irmãs e, em alguns casos, a própria mãe são ou foram mães adolescentes. Constata-se uma valorização da maternidade, onde ser mãe equivale a assumir um novo status social, o de ser mulher.

Surge, assim, o trinômio: adolescente-mãe-mulher, onde a gravidez é a via de acesso à feminilidade. A afirmação social nesse meio se expressa na maternidade, o que possibilita dizer que se trata, nesse caso, de uma gravidez social, isto é, maternidade social. Através do filho, essas jovens se sentem mães e mulheres.

Leila

"Estou me sentindo superbem com a gravidez, antes eu era uma criança, era boba, agora não, eu sei das coisas que vão acontecer, entendeu? Eu penso em trabalhar, penso no futuro, ter o meu filho, mais nada, só isso que eu penso" (Dadoorian, 2000a, p.145).

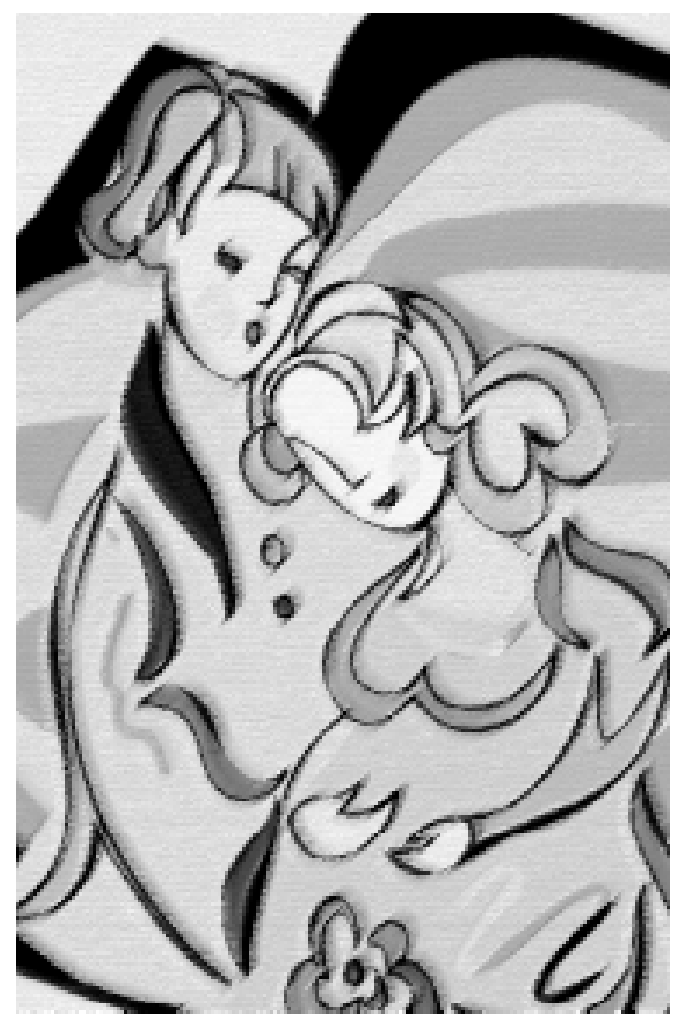

"Otermo maternidade só inclui qualidades como criar, produzir, gerar. Desta forma, quando se relaciona feminilidadee maternidade, não é só de filho que se está falando. Outros objetos podem se colocar como equivalentes ao falo/filho, como os estudos, a profissão, etc. Obviamente estes objetos não anulam, nem substituemo desejo do filho, mas, por metáfora, permitem que, atrovés deles, a mulher possa também se sentir plena, "completa"e realizada."

Figueiredo, M.A.

Já no que concerne à adolescente de classe média, verifica-se igualmente a confluência dos fatores culturais e psicológicos na determinação do destino da gravidez hormonal. Nesse meio cultural, 
a maternidade é, geralmente, indesejada na adolescência. A pressão social familiar da classe média se expressa mais através do incentivo ao estudo e ao trabalho, possibilitando que essas jovens vivam de modo mais prolongado sua adolescência, contrariamente às adolescentes de classes populares, onde a maternidade interfere nesse ciclo. Logo, a faculdade e o trabalho atuam como objetos reparadores narcísicos, ou seja, eles assumem o valor de falo, e o desejo de ter um filho pode, assim, ser adiado para a vida adulta.

Juntamente com os fatores culturais, os fatores psicológicos também são determinantes nessa questão. Freud, no seu texto Sobre o narcisismo: uma introdução, nos mostra que o tipo de escolha

\section{"O filho representa} uma porção de coisas, tudo de bom; a coisa que eu mais tenho no mundo é ele. Eu vou ter alguém para ficar do meu lado, se eu sofrer é uma pessoa que vai ficar perto de mim"

Silvia

(Dadoorian, 2000a, p.147).

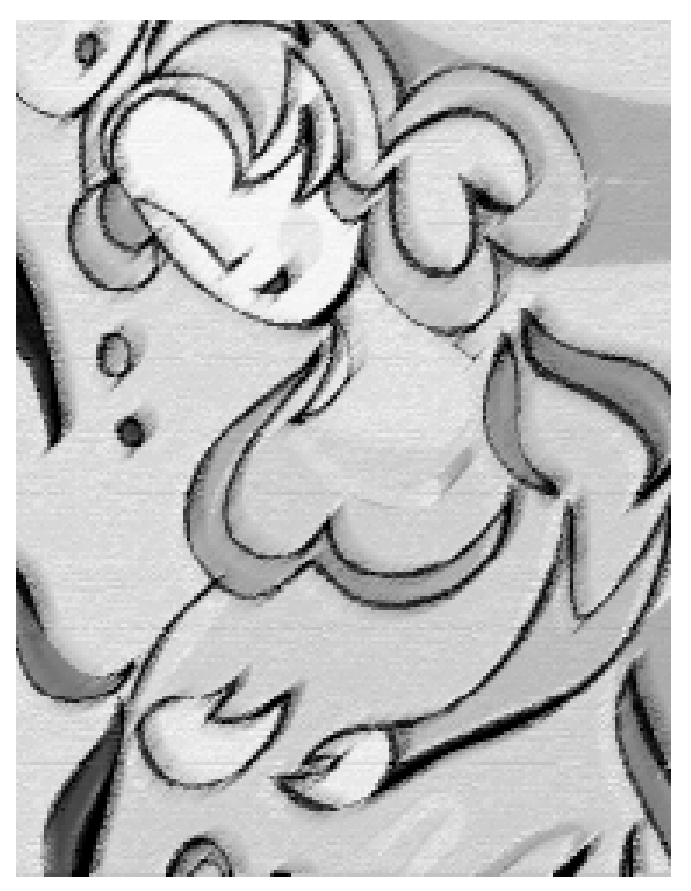

amorosa feminina que leva ao amor objetal completo se expressa através da maternidade, onde a mulher transfere para a criança (objeto estranho e que é, ao mesmo tempo, extensão do seu corpo) o seu próprio narcisismo. O desejo de ter um filho, isto é, o desejo universal do falo, representa a possibilidade de restauração do seu próprio narcisismo infantil abandonado.

Por outro lado, pressupõe-se na pesquisa que, para essas jovens, por terem uma precária situação econômica que lhes dificulta o acesso a bens de serviço e a serviços essenciais, o falo aparece como o objeto privilegiado capaz de possibilitar essa reparação narcísica. As jovens mães entrevistadas durante a investigação relataram que o filho representa "tudo" para elas e que elas desejam o melhor para eles, que eles estudem, trabalhem e que não lhes falte nada .
Silvia

"O filho representa uma porção de coisas, tudo de bom; a coisa que eu mais tenho no mundo é ele. Eu vou ter alguém para ficar do meu lado, se eu sofrer é uma pessoa que vai ficar perto de mim" (Dadoorian, 2000a, p.147).

\section{Família e gravidez na adolescência}

Fátima

"O filho representa tudo, tudo de bom, muita felicidade. Espero que ele traga muita união da minha família comigo" (Dadoorian, 2000a, p.150).

As famílias das adolescentes entrevistadas apresentam uma média de quatro filhos por família, fato esse que se articula com a noção de filho como um bem, um valor, para essa classe social. $O$ desejo de ter o filho repararia a carência narcísica dos próprios pais, que moram na favela, são malremunerados no trabalho e não têm condições econômicas para terem um melhor nível de vida.

Os pais incentivam a união das filhas com os seus namorados quando elas iniciam a vida sexual, valorizando desde cedo o casamento.

A relação mais intensa se estabelece com a mãe e expressa numa ambivalência de sentimentos, de ódio e de amor. Observa-se também uma carência afetiva das jovens e a necessidade de terem um nível de diálogo mais satisfatório com a mãe, principalmente no que se refere à questão da sexualidade.

As adolescentes vivenciam uma grande solidão agravada pela "carência de afeto" de seu meio familiar, e, dessa forma, a carência afetiva as leva à maternidade. A jovem transfere para o filho essa demanda de amor. O filho é, assim, o depositário de muitas expectativas: ele terá tudo o que elas não tiveram: estudo, carinho, proteção e até uma família.

Inicialmente, a família da adolescente não reage favoravelmente à gravidez da filha, afirmando que ela é muito nova. Entretanto, após esse primeiro momento, elas aceitam esse fato posicionando-se inclusive contra o aborto. A gravidez da jovem é vivida por toda a família, sendo o filho um traço de união entre eles.

Com relação ao interesse da mãe da adolescente pelo seu neto, é um fato bastante observado que se expressa na fala das avós, dizendo que a filha é muito nova e que não sabe cuidar da criança. A maioria das adolescentes entrevistada nesta pesquisa relatou que iam deixar o filho com a mãe para poderem ir trabalhar. Essas situações revelam o falo (filho) como um presente da adolescente para a sua mãe. Por outro lado, por meio da maternidade da filha, a mãe revive, mais uma vez, 
o seu desejo de completude, de reparação de suas carências afetivas.

\section{Informação $\mathrm{x}$ desejo}

\section{Carmem}

"Nunca me interessei em saber sobre esses métodos. Sabia que podia engravidar, não usei porque eu queria um filho mesmo. Aí casei e nem tomei remédio. Porque eu achava legal um filho para eu cuidar e as minhas colegas todas tinham, só eu que não tinha" (Dadoorian, 2000a, p.149).

Todas as adolescentes entrevistadas afirmaram ter conhecimento de que exercer a atividade sexual sem o uso de contraceptivos poderia provocar uma gravidez. Entretanto, elas relataram que não fizeram uso desses métodos quando iniciaram a sua vida sexual. Esse dado questiona o fato de que a gravidez na adolescência ocorreria em função da desinformação sexual, como afirma o enfoque tradicional. Algumas adolescentes consultaram ginecologistas levadas por suas mães, mas, mesmo nesses casos, elas optaram por não utilizar anticoncepcionais.

A fala das adolescentes para explicar o não-uso de contraceptivos confirma o seu desejo de ter um filho.

No que tange aos programas de educação sexual, as adolescentes se mostram interessadas na aquisição de informações acerca dessa questão, e relatam que em alguns colégios tiveram aulas sobre esse tema. No entanto, a maioria dessas jovens afirma que a educação sexual deveria iniciar-se em casa, com os pais, especialmente com a mãe, pois estes têm mais intimidade para falar sobre esse assunto com os filhos. Essa escolha reforça o desejo das adolescentes no estabelecimento de um maior nível de diálogo com os pais.

\section{Escola e gravidez na adolescência}

\section{Cristina}

"Estou na $1^{\mathrm{a}}$. série do ensino médio, é escola pública. Vou continuar estudando. A diretora disse que quando eu ganhasse, que era para eu levar uma declaração para ficar alguns dias em casa. Ninguém falou nada. Na minha sala também tem uma pessoa com dois meses" (Dadoorian, 2000a, p.119).

Todas as adolescentes entrevistadas freqüentavam escolas públicas, no entanto, a maior parte delas não estudava e não trabalhava. $\mathrm{O}$ abandono dos estudos não se dava pela rejeição do colégio à situação da gravidez, mas, sim, por sentimentos ambivalentes das jovens, de vergonha, como que para negar que exercem a sua sexualidade, ou de satisfação pela gravidez, visto que algumas delas relatavam que só queriam "curtir" o filho. A esses fatores emocionais, se junta a falta de estímulo dos pais, que valorizam mais o trabalho, através do qual a jovem poderá ajudar na renda familiar, do que os estudos das filhas. O fato de não concluírem a escolarização traz dificuldades para alcançarem a independência financeira e profissional.

A atitude da escola frente a essa situação varia bastante. Em geral, as escolas públicas convivem melhor com essa situação do que as escolas privadas.

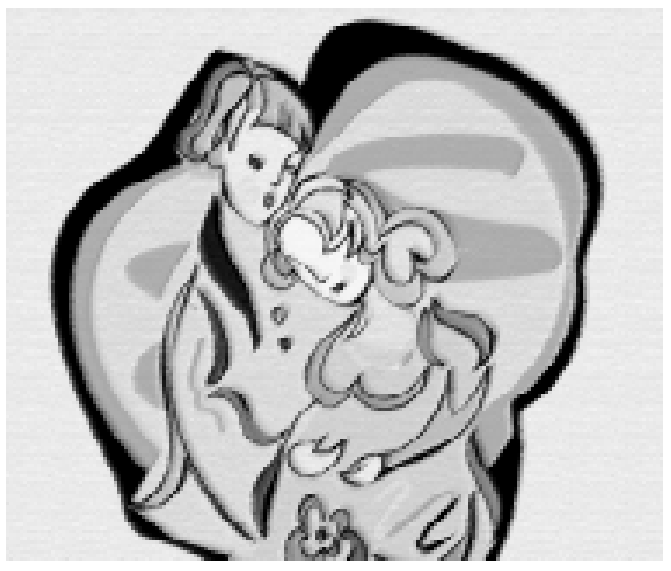

Aborto

Rita

"Tenho muito conhecimento, mas não fiz nenhum porque eu não queria abortar, já estava sentindo amor desde o primeiro mês, o feto na minha barriga, embora o meu marido não quisesse aceitar eu já sentia" (Dadoorian, 2000a, p.157).

A decisão de interromper ou não a gravidez está intimamente relacionada com os aspectos psicossociais, como vimos anteriormente.

Em nossa pesquisa, praticamente todas as adolescentes entrevistadas rejeitaram o aborto, afirmando a decisão de ter o filho. As jovens relatam que querem ter o filho, pois gostam de criança, além de o filho ser percebido como alguém que não vai abandoná-las. O aborto é rejeitado por essas adolescentes que afirmam ter decidido ter o filho. Além do aspecto religioso presente nessa questão, essa atitude aponta que o feto já é percebido como o seu filho, pelo sentimento de afeição com que ele é referido pelas jovens.

\section{Projetos de Vida}

Nenhuma das adolescentes entrevistadas tinha planos para o futuro. As suas perspectivas de vida se resumiam a um futuro imediato, situado logo após a gravidez, onde elas relataram que
No que tange aos programas de educação sexual, as adolescentes se mostram interessadas na aquisição de informações acerca dessa questão, e relatam que em alguns colégios tiveram aulas sobre essetema. No entanto, a maioria dessas jovens afirma que a educação sexual deveria iniciarse em casa, com os pais, especialmente com a mãe, pois estes têm mais intimidade para falar sobre esse assunto com os filhos. Essa escolha reforça o desejo das adolescentes no estabelecimento de um maior nível de diálogo com os pais. 
pretendiam cuidar do filho e trabalhar para poder educá-lo.

\section{Conclusões}

"Crescei-vos e multiplicai-vos..." Gênesis, 1,22.

A constatação da grande incidência de gravidez levada a termo em adolescentes de classes populares e a insuficiência dos referenciais teóricos explicativos indicou a necessidade de se investigar o significado da gravidez através do discurso dessas adolescentes sobre o seu estado e da influência dos fatores culturais e psicológicos.

A partir dessa análise, pode-se dizer que as causas da gravidez na adolescência não se referem exclusivamente à desinformação sexual, mas ao desejo universal de ter um filho na adolescência, seja para a adolescente testar a sua feminilidade através da constatação da sua capacidade reprodutiva, seja pelo próprio desejo de ter um filho.

Dessa forma, a gravidez na adolescência pode surgir tanto decorrente do imperativo biológico, isto é, do impulso na direção de sua capacidade reprodutiva (espécie) como do seu próprio desejo de ter um filho (indivíduo).

"O filho representa uma porção de

coisas, tudo de bom; a coisa que eu mais tenho no mundo é ele. Eu vou ter alguém para ficar do meu lado, se eu sofrer é uma pessoa que vai ficar perto de mim"

Silvia

(Dadoorian, 2000a, p.147).
Ao analisar o contexto social dessas jovens, observase que a função social feminina está relacionada à maternidade, ou seja, ser mulher para essas adolescentes equivale a ser mãe. $O$ desejo de ter um filho é um rito de passagem, uma mudança substancial no status: de menina para mulher. Evidenciou-se que a vivência de situações de carência afetiva e relacional com a família pode também provocar o desejo na adolescente de ter um filho, em que este aparece como o objeto privilegiado capaz de reparar essa carência.

Por isso, a questão que se evidencia não é a falta de informação, mas a falta de formação. Fornecer o conhecimento sobre as questões referentes à fisiologia sexual e às práticas contraceptivas é uma política insuficiente e pouco eficaz para evitar as graves conseqüências que daí advém. O canal que leva essa informação deve se abrir e se permeabilizar à complexidade do universo psicossocial dessas adolescentes, particularizando a significação da gravidez nesse segmento social.

É importante salientar que os enfoques tradicionais até aqui utilizados tratam essa questão a partir da idéia de que a gravidez na adolescência é indesejada, ou seja, através da ótica dos profissionais de saúde. Não se valoriza o discurso o fracasso de vários projetos de educação sexual,

visto que os desejos e fantasias dessas adolescentes quanto à sua gravidez não são priorizados.

Portanto, é oportuno ressaltar que as propostas de intervenção, tanto na área médica, como na psicológica ou sócio-educativa com essas adolescentes devem igualmente priorizar o significado dessa gravidez e suas implicações subjetivas e culturais, para que sejam obtidos resultados mais eficazes, o que proporcionaria um aumento do número de gravidezes planejadas e uma diminuição do número de gravidezes "acidentais".

Uma análise mais aprofundada dessa questão mostra que a jovem que será filha e mãe ao mesmo tempo terá características diferenciadas e dificuldades próprias na elaboração das diversas etapas evolutivas de sua sexualidade, ficando, assim, prejudicada a vivência da maternidade. O filho aparece, em muitos casos, como um presente da adolescente para a sua própria mãe. No entanto, apesar das dificuldades encontradas, essa situação não altera de forma drástica o desenvolvimento da sexualidade dessas jovens, como muitos especialistas fazem crer. Devemos, portanto, ser cuidadosos para não traçar um quadro mais trágico e pessimista do que ele é na realidade.

A ausência, nas adolescentes que optam pela gravidez, de uma visão mais abrangente sobre o seu estado gera conseqüências que repercutem em dois níveis: no individual, que se refere aos aspectos psicológicos expressos em cada uma dessas adolescentes, e no social, isto é, nos aspectos sócio-econômicos, na medida em que a gravidez em adolescentes, sobretudo em jovens provenientes de classes populares, multiplica as condições de reprodução da pobreza econômica e social .

Essas conclusões apontam para a importância dos aspectos psicossociais presentes nessa questão. Logo, se quisermos pensar em propostas preventivas, é de fundamental importância a presença do psicólogo, no dia-a-dia das adolescentes e de suas famílias: nas escolas, nos hospitais e nas associações comunitárias. Dessa forma, ele poderá acompanhar o desenvolvimento das jovens, ajudando-as e às suas famílias a elaborar os conflitos que daí possam surgir. As instâncias governamentais deveriam, assim, ampliar o número de cargos oferecidos a esses profissionais nessas instituições.

Acreditamos portanto, que o psicólogo pode contribuir de forma significativa para o estudo, a prevenção e a formulação de novas propostas de trabalho sobre temas de grande importância na realidade social brasileira, como o é a questão da gravidez na adolescência. 
Aries, P. (1981). História Social da Criança e da Família. Rio de Janeiro: Guanabara.

Dadoorian, D. (2000a). Pronta para voar, um novo olhar sobre a gravidez na adolescência. Rio de Janeiro: Rocco.

(2000b). La Grossesse désirée chez les adolescentes dans les milieux défavorisés. Quelques réflexionsà partir d'une étude réalisée au Brésil. Neuropsychiatrie de l'enfance et de l'adolescence, 48, n.1, 44-50.

(1999). Children who make children... Trabalho apresentado no $V$ Congresso Internacional da ISAP (International Society of Adolescent Psychiatry), Aix-en Provence, França.

(1998). A gravidez desejada na adolescência. Arquivos Brasileiros de Psicologia, 50, n.3, 60-70.

(1996). Adolescentes: Porque elas querem engravidar? Femina, 24, n.1, 47-51.

(1994). A gravidez desejada em adolescentes de classes populares.

Dissertação de Mestrado, Pontifícia Universidade Católica do Rio de Janeiro, Rio de Janeiro.

Doering,K. (1989). As adolescentes e o início do relacionamento sexual. Femina, 17,n.3.

Figueiredo,M.A. Útero. wnw.seadog.com.br.
Freud,S. (1905). Três ensaios sobre a teoria da sexualidade. Ed.Standard Brasileira das Obras Completas de Sigmund Freud. Rio de Janeiro: Imago.

(1914). Sobre o narcisismo: uma introdução. Ed.Standard Brasileira. Rio de Janeiro: Imago.

(1931).Sexualidade Feminina. Ed.Standard Brasileira. Rio de Janeiro: Imago.

Hassoun, P-L. (1995). Freud et la femme. Paris : Payot\&Rivages.

Lo Bianco, A.C. "A psicologização do feto". Em Figueira,S. (Org.), Cultura da psicanálise (pp.94-115). São Paulo: Brasiliense, (1985).

(1986). "Ideal"e "realização" familiares em dois grupos sociais da cidade do Rio de Janeiro. Trabalho apresentado no Seminário Nacional sobre relações familiares. Campinas, Brasil.

Mazet, P. \& Houzel, D. (1993). Psychiatrie de l'enfant et de l'adolescent. Paris : Maloine.

O.M.S. (1988). Learning to be parents an annotated bibliography of programmes for young people. (TAP/672). Genebra.

Salem, T. (1981). Mulheres faveladas: "com as vendas nos olhos". Perspectivas Antropológicas da Mulher 1. Rio de Janeiro: Zahar.

Silva,J.L. \& Pinotti,J. (1987). A saúde reprodutiva da adolescente. 